Enrique Barros Bourie - Honra, Privacidad e Información: Un crucial...

\title{
HONRA, PRIVACIDAD E INFORMACIÓN: UN CRUCIAL CONFLICTO DE BIENES JURÍDICOS
}

\author{
Enrique Barros Bourie \\ Profesor de Derecho Civil y Filosofía del Derecho \\ Universidad de Chile
}

En la conferencia que voy a presentarles, trataré uno de los temas que tienen que ver con el conflicto de la relación recíproca entre los bienes de la libertad de información, la honra, la privacidad, la intimidad, como es el tema de la privacidad como secreto, vale decir, el derecho o la pretensión que tenemos de que muchas cosas o muchos asuntos en nuestras vidas privadas estén exentas del conocimiento, y no sólo del juicio ajeno. Sin embargo, para eso hay que establecer algunas relaciones con otros bienes comprometidos, por lo que también me referiré a los límites y a las diferencias conceptuales que existen entre la honra, por un lado, y la privacidad por el otro, porque son bienes distintos, y están protegidos de una manera diferente, tanto en nuestro ordenamiento como en el derecho comparado.

II

La noción jurídica de privacidad posee en verdad un significado difuso, al que son asociadas cuestiones que presentan sólo remotas analogías recíprocas, y cuya enorme fuerza expansiva parece asociarse al creciente desarrollo de instituciones de protección de la individualidad en las sociedades liberales contemporáneas. Así, en su sentido jurídico más originario la idea de privacidad, lo privado fue asociado a los llamados derechos a la personalidad, cuyo fundamento es la autoridad que se reconoce a la persona respecto de sí misma en sus relaciones con los demás. Por eso, en un sentido genérico, como el referido en la Constitución Política, el derecho a la vida privada más bien denota un ámbito, un conjunto de bienes dentro del cual co-actúan diversos derechos e intereses.

En una primera línea de desarrollo, que en Chile es desconocida, pero que en el derecho comparado ha sido extremadamente importante, la privacidad ha servido de fundamento para expandir el ámbito de autodeterminación de las personas y, particularmente, el ámbito de la autodeterminación moral del individuo, limitando la esfera en que una persona puede ser sancionada coactivamente por el Estado. En este sentido, la privacidad ha fundado nuevos límites, antes desconocidos, al control por parte del Estado de importantes ámbitos de la vida personal.

Así, en el derecho comparado la privacidad ha sido frecuentemente fundamento de decisiones constitucionales que excluyen del control por el Derecho a ciertas materias, como por ejemplo la vida sexual de las personas. El punto más extremo de este desarrollo de la privacidad concebida como autodeterminación en el terreno moral, está en el fallo de la Corte Suprema norteamericana que ya tiene más de 20 años, en "Roe 
versus Wade", que declaró como un caso de aplicación del principio constitucional de la privacidad, que por lo demás no está expresamente señalado en la Constitución norteamericana de fines del siglo XVIII, el privativo derecho de la mujer embarazada para decidir acerca de un aborto en el primer período de embarazo. La Corte Suprema norteamericana declaró inconstitucionales las leyes de los Estados Federales que sancionaban el aborto, y esa jurisprudencia se ha mantenido -con algunas leves modificacioneshasta ahora.

Pero más allá de esos territorios sin fronteras, el desarrollo de la privacidad como autodeterminación en terreno moral no ha sido objeto de desarrollo en Chile, y es muy probable que no sea esa una fuente de desarrollo jurisprudencial en materia constitucional. En verdad, en su contenido, en su núcleo más duro, el derecho a la privacidad se traduce, como lo ha definido Charles Fried, un muy notable profesor de Harvard, en un control que tenemos sobre la información acerca de nosotros mismos, y ese es básicamente el sentido en que lo voy a usar en esta conferencia. En este sentido, la privacidad expresa un poder para excluir a personas no autorizadas del conocimiento de hechos que quedan bajo el control exclusivo de cada cual. Para ello la privacidad establece dos limitaciones conexas entre sí, pero diferentes. Por un lado, este ámbito de privacidad impide que terceros se introduzcan, por cualquier medio, en ámbitos físicos de intimidad, y por otro, que se difundan hechos relativos a un ámbito concebido como privado. Vale decir, primero tiene este sentido de inviolabilidad del ámbito físico de privacidad, y en segundo lugar, cautela que no se difundan informaciones acerca de aquello que es concebido como privado.

En su primer aspecto, la privacidad establece un límite a la indagación, a la forma como se investigan hechos privados. Así, por ejemplo, es ilícita la intrusión en el ámbito físico de recogimiento o aislamiento de una persona, en su vida familiar o profesional. El objeto de este aspecto del derecho de la privacidad es establecer límites a la manera como se obtiene información acerca de la forma de vida de las personas, inclinaciones o aspectos íntimos; expresado en el lenguaje corriente, esta forma del derecho de privacidad establece una defensa frente al espionaje de la vida privada.

La materia es desde luego decisiva en el Derecho Público y tiene que ver con las limitaciones que el Derecho impone al Estado para que controle la vida privada con fines de control político-criminal. Aunque menos dramático, este aspecto de la privacidad, sin embargo, también es muy importante en las relaciones entre sujetos privados. Se estima así ilícita la intrusión por cualquier medio físico en el ámbito de soledad personal, aunque luego nada se diga, publique o archive. Por lo mismo, la ilegitimidad de la intrusión en el ámbito físico de privacidad, está dada por el hecho de intervenir en ese ámbito físico de retraimiento o en una comunicación personal, como es por ejemplo la inviolabilidad de la correspondencia, con independencia de la relevancia pública que pueda tener esa información. En estos casos, el ilícito está dado por el hecho de la intrusión en un ámbito de intimidad legítimo, sea mediante invasión física del hogar o del lugar de trabajo, sea mediante instrumentos técnicos para grabar, filmar, o de cualquier modo entrometerse en el ámbito físico ajeno, lo que naturalmente se extiende a conversaciones privadas, a comunicaciones escritas cuyo destinatario esté definido por el autor.

La irrupción en la intimidad física de una persona, excepcionalmente puede producirse incluso en lugares públicos. Aquí quisiera hacer una pequeña alusión, para sa- 
lirme del terreno abstracto en que he formulado la cuestión anterior, a las llamadas "revistas de corazón". A un fotógrafo que alimenta de material a esas revistas le resulta perfectamente lícito captar imágenes en una playa, en una calle, incluso en un lugar privado, siempre y cuando la imagen sea captada desde un lugar público, y es así como se publican fotografías de estas personas de cierta notoriedad, que han sido captadas desde lugares públicos en sus ámbitos privados. Pero irrumpir físicamente en el lugar de intimidad resulta ilegítimo. Esa sutil diferencia es la que establece este ámbito físico de intimidad.

Lo anterior, sin embargo, no significa que no haya ámbitos de privacidad en espacios públicos. Así, por ejemplo, si una persona, por medio de instrumentos técnicos refinados, capta una conversación que se produce en la vía pública, por el hecho de ser una conversación privada, a pesar de estar produciéndose en la vía pública, es concebida como una intrusión en la intimidad física de las personas involucradas.

El caso más notable en el Derecho Comparado ocurrió inmediatamente después de la muerte del Presidente Kennedy. Un fotógrafo italiano perseguía a la viuda del Sr. Kennedy por todos los lugares públicos en los cuales se desplazaba. Esta recurrió ante la Corte solicitando que se le protegiera, precisamente en razón de la intimidad, y la Corte determinó -en una fórmula muy americana- que el fotógrafo no podía acercarse a la viuda del Sr. Kennedy a una distancia inferior a los $6 \mathrm{mts}$., porque eso significaba limitarle su espacio físico de intimidad. El fallo muestra que la privacidad emprende la capacidad física de desplazamiento, pero en ningún caso la de mantenerse excluido del conocimiento público.

III

De distinta entidad es la privacidad como secreto, que es básicamente el tema que quisiera analizar en esta conferencia. Esto es, la pretensión que todos tenemos de que ciertos hechos relativos a nuestra vidas ordinarias y a nuestra inclinaciones y particularmente a nuestra debilidades físicas o morales, no puedan ser objeto de conocimiento por terceros. Es característico de este aspecto de la privacidad, que resulte indiferente, y éste es un problema jurídico esencial que hace la diferencia con la difamación y con los delitos de injurias y calumnias: resulta indiferente la verdad o falsedad de los hechos que son objeto de la información. Aquí lo que se protege es el secreto y, por muy verdadero que sea un hecho perteneciente a esta esfera de privacidad, la divulgación de ese hecho verdadero, por el sólo hecho de afectar la privacidad, resultaría ilícito.

Tampoco es necesario que este hecho afecte el prestigio de una persona, o su vida de relación; basta que afecte la autoestima o le cause simplemente un serio embarazo. Todo ello establece una frontera que es necesario analíticamente tener muy clara, entre la privacidad por un lado, y la difamación, la injuria y la calumnia por el otro. Mientras la difamación se caracteriza por la difusión de hechos falsos que afectan la honra, lo importante en materia de privacidad es simplemente el valor personal del secreto. En lo sucesivo me referiré entonces a este concepto de privacidad como secreto.

En el más famoso documento jamás escrito en materia de la privacidad, indudablemente uno de los escritos jurídicos más finos y más sutiles que se hayan jamás escrito en materia de derecho privado y de los límites entre derecho privado y constitu- 
cional, los abogados de Boston, Brandeis y Warren - uno un gran abogado, el otro alguien que llegó a ser un famoso Ministro de la Corte Suprema- plantearon con elegante dramatismo hace ya un siglo argumentos que se siguen reiterando después de una centuria. Escribían en la Revista de Derecho de la Universidad de Harvard, en el año 1890: "La prensa está superando los limites obvios de lo propio y de lo decente. El chisme ya no es un recurso del haragán y del vicioso, sino ha devenido en un negocio ejecutado con tanta aplicación como desvergüenza. Para satisfacer el gusto lascivo, detalles de intimidades sexuales son difundidas en las columnas de los periódicos. Para satisfacer al insensible, unas tras otras las columnas están llenas de chismes que sólo pueden ser obtenidos mediante incursiones en el ámbito de lo doméstico". Así partía el artículo de Brandeis y Warren. Pareciera que los conceptos siguen dando vuelta en nuestras conciencias.

Una importante habilidad retórica de estos autores es oponer el ámbito de lo íntimo, excluido de la mirada y el escrutinio público, por un lado, respecto del interés de la prensa, por el otro, interés por una basura que produce beneficios injustos en opinión de estos abogados. Los intereses en juego aparecen así en un fuerte contrapunto de luz y de sombra, que tiende a dar una fuerte primacía naturalmente a la vida privada por sobre la información.

Tales valoraciones intuitivas en que la vida privada tiene un predominio sobre la libertad de información, probablemente han llevado a que en una famosa reciente sentencia de protección en este país, se haya fallado que no es lícito divulgar hechos relativos a la vida privada -estoy citando el fallo de la Corte de Santiago, en el caso Martorell- "por encontrarse el ejercicio de la libertad de expresión restringido por un derecho de mayor jerarquía como es el consagrado en el Art. 19 № 4 de la Constitución Política". La Corte de Santiago llegó a decir que el 19 № 4 primaba sobre la libertad de información, por una especie de orden lexicográfico, en que las garantías constitucionales de los primeros números del art. 19, tendrían prevalencia sobre las posteriores. La Corte Suprema agregó como consideración a su sentencia confirmatoria del fallo que ordenó la protección, lo siguiente: "Que el respeto de la vida privada y de la dignidad y honra de la persona humana constituyen valores de tal jerarquía y trascendencia que la sociedad política se organiza precisamente para preservarlos y defenderlos, de modo que no puede admitirse concepción alguna del bien común que permita el sacrificio de ellos ni convertir tal sacrificio en medio para que prevalezca otra garantía constitucional, en este caso la libertad de expresión" (considerando $3^{\circ}$ del fallo de la Corte Supre$\mathrm{ma})$.

No es mi propósito discutir la parte resolutiva del fallo. Como todo libro prohibido, el de Martorell fue de amplia circulación, y verdaderamente se trataba de un libro despreciable. El fallo de la Corte de Santiago y el de la Corte Suprema dan por establecido, como digo, un estricto orden jerárquico de derechos, en que la vida privada jamás estaría abierta al conocimiento público en razón de constituir un derecho superior al de la libertad de información.

En verdad los casos más difíciles de conflicto entre privacidad y libertad de expresión exigen una discusión mucho más sutil acerca de su alcance recíproco. En pocos ámbitos del Derecho se ven con más claridad los límites de un análisis abstracto, en torno a derechos planteados en términos excesivamente categóricos. En definitiva, el conflicto entre privacidad y libertad de expresión no puede ser resuelto a partir del 
análisis del texto constitucional, porque todo texto constitucional, por lo concentrado de su formulación, es semánticamente pobre. Ante todo, el ámbito de aplicación queda indeterminado en la Constitución por la imprecisión de las palabras que el propio texto constitucional emplea : "vida privada", "vida pública de una persona". Por otro lado, un enunciado tan general necesariamente deja intersticios, que impiden dar cuenta de casos o situaciones que resultan imprevisibles al momento de redactar la norma.

Asimismo tenemos que tener claro que la historia fidedigna de las normas constitucionales vigentes es sintomática de la preferencia de los comisionados constituyentes por cautelar el secreto de la vida privada, como se mostró al rechazar la Comisión de Estudios de la Nueva Constitución una indicación de su miembro Sr. Jorge Ovalle, en orden a que la vida privada sólo se cautelara frente a intervenciones arbitrarias, lo cual dio lugar a un debate al interior que fue zanjado por la mayoría en el sentido que era necesario borrar la palabra "arbitraria", porque eso significaría eventualmente un debilitamiento del principio de privacidad. Sin embargo, esta historia particular que tiene la norma del 19 № 4, en mi opinión, debe ser relativizada como fuente de autoridad interpretativa, particularmente en el actual desarrollo y desenvolvimiento jurídico y político de este país.

Por eso, en Chile, como en todos los sistemas jurídicos maduros, los límites sólo podrán establecerse a la siga de una comprensión más reflexiva que la actual, del sentido y alcance de los bienes e intereses subyacentes. Vida privada por un lado y libertad de expresión por el otro.

\section{IV}

En lo sucesivo, me voy a referir a un conjunto de argumentos que me parecen decisivos para justificar la razón por la cual el Derecho debe proteger la privacidad, y en seguida, me voy a referir a un conjunto de argumentos de por qué la privacidad debe ser relativizada. En consecuencia intentará identificar, buscar los argumentos que en el Derecho Comparado y en la Filosofía Jurídica Comparada se han dado para justificar la prevalencia de uno u otro derecho. Y confío que luego de este análisis tendremos elementos de juicio adicionales.

En sus orígenes más remotos el derecho a la privacidad se asocia a las libertades del espíritu. Su objeto era que la conciencia, la fe religiosa, la opinión y el saber no estuviesen sujetos al control público del estado de policía. La hipertrofia de lo público en esa época produce en la modernidad temprana, como primera reacción, la cautela de un ámbito interno de privacidad. El estado tiene el control de la conducta externa, pero jamás va a tener el control de la interioridad. Sin embargo, esas libertades de conciencia, de religión y del saber científico no se agotan en la esfera privada; por su naturaleza tienden a manifestarse en el ámbito público, de modo que las libertades de opinión y expresión no sólo constituyen su correlato puramente lógico, sino también su condición de eficacia para el progreso de las ideas, la consolidación de la religión y el desarrollo de la ciencia.

Por eso, pienso que la privacidad como secreto presenta más relaciones con la propiedad que con aquellos bienes como la libertad de conciencia, que están más orientados precisamente hacia lo público, con los que intuitivamente sin embargo aparecen estar más relacionados. En efecto, la propiedad es la garantía que autoriza a excluir a los demás del goce legítimo de algo reconocido como privado. 
La privacidad, más allá de nuestra relación exclusiva con las cosas, como ocurre con la propiedad, supone sustraer del concepto público un ámbito particular de nuestra vida. Desde esta perspectiva, la privacidad aparece históricamente como un derecho de la personalidad, como un poder disponer de sí mismo según leyes provenientes de la propia razón práctica, para expresarlo en términos radicalmente kantianos.

Ello se expresa, creo, en contraste con una sociedad perfectamente totalitaria. En 1984 -esa pesadilla totalitaria de George Orwell-, no hay secretos excusables para nadie, como tampoco los ha habido en las dictaduras del mundo real. Todo dictador quisiera meterse en la conciencia y en la vida privada de cada cual. Sin embargo, aun en tales circunstancias, los verdaderos protagonistas suelen ser personas cuyas inclinaciones y formas de vida están alejadas del concepto oficial de lo correcto; estas personas sólo logran subsistir precisamente en la medida en que logran mantener las formas de vida como privadas. La privacidad como secreto muestra en estos casos extremos su función de garantía o autonomía personal, precisamente en situaciones en que no hay secreto legítimo.

Pero también en una democracia constitucional la privacidad parece ser condición necesaria para que se desarrolle el sentimiento de que tenemos control sobre nuestras propiass vidas. Cualquierā supresión ràdical de la privacidad conduce en que nos transformemos en miembros de lo que José Joaquín Brunner, en una conferencia en que nos tocó conjuntamente participar en la Universidad de Chile, llamó esa pertenencia a una especie de "muchedumbre solitaria", donde el sentido de identidad personal estaría irrecuperablemente dañado.

La privacidad, en cierto sentido, es condición de nuestra identidad, particularmente en esta sociedad de masas, en esta sociedad relativamente abstracta en que tenemos relaciones funcionales mucho menos afectivas que las tradicionales.

En esta misma línea de pensamiento, la privacidad ha sido justificada a la luz de una mejor comprensión de formas de vida especialmente afectivas. Este es un argumento que a mí me ha parecido extremadamente persuasivo cuando he estudiado el tema. Charles Fried ha mostrado que las relaciones humanas de mayor intensidad suponen que lo privado llegue a ser objeto de un don. Es un hermoso concepto que tiene una raigambre cristiana indudable. Supone que lo privado llegue a ser objeto de un don, de una renuncia, y no de un derecho exigible por terceros. El amor, la amistad, la confianza tienen por antecedente ese capital moral privativo de quien lo da, que es el secreto de sí mismo. Develar un secreto es un acto de don y no un derecho del otro. Abrirse a quien se ama, se estima como amigo o se confía, es un acto de disposición de lo propio, y su valor reside precisamente en que nos desnudemos selectivamente en nuestra intimidad hacia aquellos con quienes tenemos relaciones más intensas. Precisamente porque respetamos la intimidad ajena, no consideramos que sea una expectativa razonable en nuestras relaciones recíprocas, puramente funcionales, que el otro abra hacia nosotros su yo más profundo. Por eso, desde esta perspectiva, la privacidad no es simplemente una ausencia de información acerca de nosotros, sino al revés, es más bien el control que tenemos nosotros mismos respecto de a quién y cómo entregamos información acerca de nosotros. Por lo demás, los diversos roles en que actuamos en nuestra vida de relación autorizan, incluso suponen, que una parte de nuestra personalidad permanezca oculta. 
Según la naturaleza de los roles, diversas son las facetas del carácter y los hechos de la vida privada que estamos dispuestos a revelar. Esta realidad sociológicamente puede ser explicada como resultado de una diferenciación funcional, en que actuamos como padres, como abogados, como profesores universitarios, como políticos, como miembros de un club, donde cada tipo de relaciones tiene sus propios códigos. Nos relacionamos selectivamente y lo que hablamos con unos es distinto de lo que hablamos con otros, y lo que mostramos a unos es distinto de lo que mostramos a otros. Desde el punto de vista estrictamente personal tenemos una disposición selectiva a mostrar algo de nosotros mismos, según el tipo de relación en que se interactúa.

En definitiva, el control de la información sobre uno mismo hace posible el despliegue diferenciado de la personalidad, que nos permite participar lealmente en juegos diferentes, sin que en ello se comprometa por completo nuestra identidad.

Por último, quisiera dar un argumento económico, en favor de la privacidad como secreto. El valor de la privacidad para el bienestar personal se muestra no solamente en el terreno de la disquisición sicológica y moral, sino también en el terreno económico. Un reciente estudio de opinión del Centro de Estudios Públicos demuestra que un $93 \%$ de los chilenos prefiere vivir en casas que en departamentos. Parte importante de los ingresos marginales de las familias chilenas es gastado en espacios cada vez más costosos, desde el punto de vista de los ingresos, ¿Qué es lo que persiguen con más espacio? Garantizar privacidad, incluso al interior de la propia familia. Yo mismo recuerdo que a la siga de actos colectivos de ocupación de terrenos en los años 70 , en la periferia de Santiago, luego de construir una choza en los terrenos que colectivamente se tomaban, el primer acto de la gente era erigir una reja divisoria con el vecino en un elemental sentido de apropiación, pero también de seclusión.

En fin, la privacidad es un bien muy valioso desde el punto de vista moral, sicológico y económico. La idea genérica de dignidad del ser humano, por lo mismo, en la cual usualmente se fundamenta el derecho a la privacidad, me parece demasiado amplia y demasiado restringida para justificar su reconocimiento como bien protegido por el Derecho. En efecto, la privacidad tiene una cara moral basada en la idea de autonomía, en la necesidad de autoafirmarse como persona que es consustancial a la idea de dignidad. Se ve desafiada por la pesadilla de la exhibición pública de todo lo que se quisiere mantener estrictamente como propio. En suma, hay fuertes razones morales y de utilidad que justifican que la privacidad como secreto sea un bien muy valioso, cautelado por el Derecho.

Veamos ahora la otra cara. ¿Qué nos dicen los partidarios de que la privacidad se mire con cuidado?. Richard Posner es probablemente el más connotado autor de Derecho y Economía, una disciplina apasionante que busca entender las instituciones jurídicas a la luz de la economía. Posner es profesor de Chicago y es probablemente uno de los intelectuales más brillantes del mundo jurídico actual. Dedicó un capítulo de un libro reciente, que se llama "El Derecho que Sobreviene", precisamente al tema de la privacidad. Y el título en que él se refiere a la privacidad es "La Protección Legal de la Cara que Presentamos al Mundo". La privacidad como protección legal de la cara que queremos presentar al mundo. 
El argumento de Posner en favor de una mayor amplitud de la libertad de información, incluso respecto de hechos típicamente cubiertos por el derecho de la privacidad, comienza con una analogía con el derecho de los contratos. Esto yo creo que a todos los expertos en el Derecho nos va a resultar familiar. Ocurre que al vendedor de una cosa le está prohibido hacer declaraciones falsas acerca de la cosa vendida, y a todos nos parece razonable que así sea. Incluso se le impone la obligación de informar acerca de los vicios ocultos y acerca de la calidad del objeto vendido, de acuerdo con reglas que son iguales en prácticamente todos los sistemas jurídicos del mundo, y además en virtud del principio de la buena fe. Nada de eso dice Posner, ocurre, por el contrario, cuando nos vendemos a nosotros mismos. Así, mientras es ilícito efectuar publicidad engañosa acerca de un producto, no parece haber límite para que hagamos publicidad maliciosa acerca de nosotros. Algunos venden su mejor sonrisa y su voz impostadamente generosa para publicitar productos, o para recomendarse como candidatos a posiciones de poder o de notoriedad. Otros, en menor escala, ocultamos todo lo que nos pueda resultar inconveniente para ganarnos la confianza ajena o para obtener ventajas comerciales, e incluso sentimentales.

Si se descarta la difamación que supone difundir hechos falsos que comprometen la honra, la privacidad parece como un manto que cubre nuestro "yo" real y deja al descubierto el "yo" que queremos, o creemos conveniente que aparezca ante los demás. Desde esta perspectiva, resulta cínicamente relevante la frase de Yago, el malvado por excelencia, en el Otelo de Shakespeare, cuando dice: "Quien me roba la bolsa roba basura, pero quien se apodera de mi nombre me roba algo que no lo enriquece y que sin embargo tanto me empobrece". Esto en la boca del mayor difamador que conozca probablemente la literatura. En suma, muchos males pueden ser evitados si la naturaleza de los Yagos que pululan por el mundo resulta oportunamente desvelada. Por eso, desde esta perspectiva nada justifica que seamos dueños de nuestra reputación ni de los juicios que los demás tienen sobre nosotros, de la misma manera como somos dueños del dinero que tenemos en el bolsillo. Aunque no somos dueños de nuestra honra, porque por lo general ésta cede ante la verdad, la privacidad supone apropiación de información que puede ser de valor incalculable para los demás; para los electores, para los empleadores, para todos los terceros con que nos relacionamos.

Dentro de ciertos límites, quisiera advertirles, en mi opinión, esta versión más escéptica acerca de la naturaleza humana ha sido típica de los grandes momentos del Derecho, que han pretendido evitar la obnubilación que produce la transferencia irreflexiva de conceptos morales al ámbito de las relaciones sociales gobernadas por el Derecho.

Aunque construir la propia imagen en los distintos tipos de relaciones no sea algo perverso por sí, como no lo es la publicidad que resalta cualidades ventajosas o positivas de un producto, puede resultar un exceso decir que tenemos un derecho a que los demás nos miren sólo por los decorados que nosotros mismos nos hemos construido. A ello se agrega una característica estructural de la sociedad moderna. Las relaciones abstractas de vecindad y la funcionalidad de las relaciones interpersonales típicas de nuestra época, hacen que la información que espontáneamente se posee respecto de los demás sea infinitamente inferior a la que había en épocas pasadas. Antes todo lo relevante que ocurría era conocido por la transmisión oral sin necesidad de ninguna prensa amarilla. El desmontaje del control social privado hace que hoy día nos movamos en un mundo de desconocidos, en que las diferencias de poderes están en gran 
medida marcadas precisamente por quien maneja más información. Asi se explica la demanda social por información, especialmente respecto de quienes están en posiciones de poder o de influencias frente al público, que se muestran desinhibidamente en calidades personales que les resultan ventajosas en su vida de relación, sin que conozcamos su cara oculta. En definitiva, tanto el voto, la sintonía, como un contrato ventajoso pueden estar más determinados por lo que se calla que por lo que se muestra.

Aquí tenemos un segundo grupo de argumentos que opera en el sentido inverso de la privacidad y en beneficio de la libertad de información. $Y$ surge entonces la pregunta. ¿Dónde dibujar la línea entre lo privado y lo público? La parte final de mi exposición se referirá precisamente a los intentos que se han hecho para trazar esta línea.

VI

Siguiendo a Wittgenstein, uno de los más grandes filósofos de este siglo, se podría decir que en estos temas jurídicos cruciales "el peor de los males, una dieta unilateral". Se ha demostrado en diversos aspectos que la privacidad resulta un bien de gran valor personal; por otro lado, la información no se justifica sólo ni siquiera primordialmente como un derecho de la prensa, como lo demostraban Brandeis y Warren ya hace un siglo, sino como un bien de interés general que es provisto por intermedio de la prensa y de los medios de difusión y que constituye una garantía constitutiva, lo que hace de la libertad de expresión un derecho condicionante de todas las demás libertades, como lo ha entendido la jurisprudencia constitucional más reflexiva en los tiempos que vivimos. De ahí que no resulte correcto un debate planteado tan excluyentemente como un conflicto entre derechos de la prensa y de las personas.

Desde esta perspectiva resulta muy discutible el supuesto orden jerárquico entre los bienes de la vida privada prevalente, y de la información subordinada, que emplea el fallo de protección que antes se comentaba. En definitiva, todo parece indicar que nuestro país participa de modo particularmente intenso de esa ambigüedad que es característica de las sociedades estructuralmente autoritarias, más allá de su sistema político, en que, como expresaba hace un siglo Edith Warton, en esa maravillosa novela La Edad de la Inocencia, la hipocresía parece ser tolerada en nuestras relaciones privadas aunque a condición de que hacia afuera se muestre una limpia e impecable honestidad. Por eso, tirar la línea divisoria entre intimidad y publicidad supone reflexionar más serenamente acerca de los caminos jurídicos más adecuados para hacerlo.

En estos mismos días dos proyectos son objeto de tramitación en el Congreso Nacional, una nueva Ley de Prensa y otra que persigue proteger la privacidad. Ante estos propósitos legislativos que en cierto sentido muestran una cierta ansiedad, conviene detenerse a reflexionar acerca de los caminos emprendidos. Se está verificando una peligrosa tendencia en este país: gobernar todos estos asuntos por la vía del Derecho Penal. En este especie de inflación penal, veo, en opinión compartida por los penalistas con los que he discutido este tema, un riesgoso camino que supone abandonar la función de clausura del ordenamiento penal, que sólo se justifica cuando los otros medios que el Derecho confiere resultan insuficientes. Una primera pregunta que debe ser planteada se refiere, entonces, a la extensión que debe tener el Derecho Penal en estas materias.

Uno de los más agudos penalistas jóvenes, el Profesor Miguel Soto de la Universidad de Chile, ha expresado esta inquietud en la forma de un desafío. El Derecho Penal 
no puede ser concebido como un ordenamiento puramente simbólico, en que a todo lo que nos parece mal se le asigna una pena. Esta tendencia que se ha mantenido en las últimas legislaturas tiende a transformar al Derecho Penal en una instrumento corriente de ordenación, abandonando su función propia, que está precisamente en el límite.

Una segunda cuestión se refiere a los roles que debieran asumir el legislador y los jueces en estas materias; por cierto que si el principal instrumento de ordenación es el Derecho Penal, sólo el legislador puede definir con precisión los ilícitos en razón del principio de legalidad, pero si se observan los caminos clásicos del Derecho Privado, hoy ampliados en Chile por el recurso de protección, puede entregarse a los jueces un rol mucho más protagónico, como ha ocurrido en el Derecho Comparado. De hecho, la protección, que ha llenado en Chile un vacio tradicional de las acciones civiles preventivas, sólo exige ponderar en los casos concretos los bienes de la privacidad y de la libertad de información que respectivamente garantiza la Constitución.

\section{VII}

Brevemente me referiré a la Protección. La sede en que se establece una acción cautelar para impedir la publicación o circulación de informaciones relativas a la vida privada depende en cada país de su tradición jurídica. Lo cierto es que la privacidad es de aquellos bienes que una vez lesionados no son reparables en naturaleza. La indemnización es un substituto del bien perdido irremisiblemente, porque como dice el antiguo proverbio: "No hay nada en el mundo más privado que un huevo hasta que se rompe".

En Estados Unidos tímidamente se ha planteado el procedimiento civil de las "injuctions", que es parecido a nuestras acciones precautorias; pero en definitiva ha prevalecido casi sin discusiones el principio de que la censura previa es inadmisible para un sistema de libertades. En Francia, por el contrario, la propia norma del Código Civil, que fue introducida en 1970 para resguardar la vida privada, autoriza a los jueces para prescribir todas las medidas tales como secuestro, incautación y otras, aptas para impedir o hacer cesar el atentado contra la vida privada. Esa norma autoriza que estas medidas sean adoptadas en referee, esto es, en un procedimiento de urgencia análogo a nuestra protección. En Alemania es generalmente aceptada en estos casos una acción de omisión, también de acuerdo con los procedimiento civiles ordinarios.

En teoría, al menos, nada impediría que en Chile se solicitara una medida precautoria en un juicio civil; sin embargo el recurso de protección ha resultado ser en definitiva un instrumento generalizado y eficaz. Substancialmente no hay diferencias entre la protección y las acciones civiles equivalentes que reconocen otros sistemas. En uno y en otro caso, sea en sede de protección o en sede civil, los jueces para dar lugar a una urgente cautela del derecho amagado se ven en la necesidad de calificar la gravedad y relevancia de los hechos, la entidad en riesgo y la manera como se ven amenazados alternativamente la privacidad si no no se da lugar al recurso o el libre flujo de información u opciones si se le da lugar.

\section{VIII}

En su enorme aptitud de desdoblamiento, esta especie de evidente jurídico ubicuo que es la privacidad tiene una cara estrictamente patrimonial y otra moral. Es curioso, pero la privacidad tiene un fuerte componente originario de carácter patrimonial. En un sentido patrimonial, los derechos de la personalidad, especialmente los vinculados al secreto de la privacidad, al nombre, a la imagen, son objeto de una titularidad 
que es del todo análoga a la propiedad. La historia de mi vida, o de una vida más interesante naturalmente, puede ser objeto de una biografía, para lo cual el editor compra al titular los derechos respectivos. La imagen y la voz pueden ser utilizadas en publicidad, pero sólo con el consentimiento del sujeto. Las creaciones artísticas industriales están protegidas por leyes especiales desde antiguo, y así si un tercero se apropia de estas calidades en beneficio propio, se da lugar a un perjuicio económico avaluable en el lucro cesante sufrido por titular del derecho, además de cualquier daño moral eventualmente sufrido. En el extremo, incluso se pueden producir casos de enriquecimiento sin causa. Un caso alemán es bien particular a este respecto. Una empresa de publicidad emplea una foto que le entrega un fotógrafo para hacer una publicidad, creyendo que estaba autorizada por la persona que aparecía fotografiada para efectos de ejercer ese derecho. En definitiva, se concluyó que no estaba autorizada y que la foto había sido obtenida en un recinto público, pero que no había sido autorizada para fines de publicidad. La persona que aparece en la foto dice: "iyo nunca he dado mi autorización!" : y quien había empleado la foto dice: "¡Pero si yo presumía que había dado la autorización!". No cabía acción de responsabilidad civil porque no había dolo ni culpa; había simplemente un error de hecho plenamente justificable y se siguió, por consiguiente, una acción de enriquecimiento sin causa que tuvo éxito en las cortes. Esto demuestra de qué manera estos derechos tienen una vertiente patrimonial muy significativa.

La información presenta un problema de apropiación muy importante. Una vez dada una información, saliéndonos del ámbito de la privacidad incluso, se transforma en bien público, y otros periódicos $u$ otros medios de difusión pueden divulgarla con la sola reserva de dar noticia de su fuente. El interés público que justifica la licitud de la publicación se extiende a este última, excluyéndola de un atributo de la propiedad, como es la exclusión de terceros. Así se ve de qué manera se entrecruzan los bienes morales y patrimoniales en esta materia.

\section{IX}

En materia de responsabilidad civil por el atentado del secreto de la vida privada, se plantea con toda crudeza el problema de determinar el ilícito civil. Y vale lo mismo para la responsabilidad civil que para la protección constitucional. Al respecto no se debe olvidar que la responsabilidad civil descansa sobre premisas diferentes de la penal, lo que se muestra en que sólo las sentencias penales producen cosa juzgada en materia civil y no al revés. Ante todo, el ilícito civil es construido a partir de un standard o patrón de conducta que sólo excepcionalmente está definido por la ley. En definitiva, el establecimiento del ilícito civil supone sopesar los bienes e intereses en juego, igual que en materia constitucional, en el caso concreto, con consideración de la forma como concurren los derechos y como se distribuyen los costos personales y sociales en favor de una u otra decisión. Ello deja sin embargo abierta la pregunta por los requisitos para que sea lícito (o ilícito) informar sobre hechos de la vida privada.

Y al respecto conviene hacer una diferenciación con la difamación. Aquí quiero hacer una brevísima disgresión. La difamación ha sido propuesta por el Senador Otero, como una causal de ilícito. Con todo, esa indicación, en mi opinión, es peligrosa, pues establece una especie de responsabilidad por divulgar hechos falsos y por el hecho simple de la falsedad; no hechos de la vida privada, sino hechos de la vida pública de una persona. El sólo hecho de la falsedad daría lugar a la figura de la difamación. Una regla 
de ese tipo estaría más allá de la frontera de lo admisible, pues significa atribuir a los medios de comunicación todo riesgo de error. En materia de difamación, la pregunta que todo sistema legal tiene que responder, es la de sobre quién tiene que recaer el riesgo de una información falsa. Si se da una información falsa, ¿quién corre el riesgo? El riesgo lo corre el periódico, el medio de difusión, o bien lo corre la persona respecto de la cual se da la información. La jurisprudencia norteamericana, que en esta materia tiene una larguísima tradición de libertad de expresión, con especial consideración del valor social de la información, ha establecido -y ésta es una jurisprudencia que se estableció en los años 50 y 60 y que ha sido extraordinariamente influyente en todo el Derecho Constitucional comparado- que respecto de figuras públicas la información falsa sólo puede ser difamatoria, esto es dar lugar a indemnización, si ha sido difundida maliciosamente o con temeraria desconsideración de la verdad. Este es el famoso precedente del caso "Sullivan con el New York Times", del año 1964, ventilado en la Corte Suprema. ¿Cuál fue el caso? Una manifestación en el Estado de Georgia, por la igualdad racial, con ocasión de la visita de Martin Luther King, fue violentísimamente reprimida por la policía. El "New York Times", al día siguiente, informó de una manera muy crítica respecto de estos hechos, y señaló que entre los participantes en la represión de la manifestación estaba el Jefe de Policía del lugar. En definitiva, el Jefe de Policía demandó al "New York Times" porque él no estaba presente en ese acto y el "New York Times" había entregado una información falsa. El Tribunal de Georgia sancionó al "New York Times" con una millonaria indemnización y la Corte Suprema de Georgia confirmó el fallo sancionatorio. El "New York Times" recurrió a la Corte Suprema, la que, en favor del "New York Times", falló estableciendo que la libertad de información no puede excluir el error, porque desde el momento que el error queda sancionado civil o criminalmente, la libertad de información se hace imposible.

Por lo tanto, la línea está precisamente en la temeraria desconsideración de la verdad, el equivalente a nuestra culpa grave. Vale decir, sólo con dolo o culpa grave hay indemnización en el caso de imputaciones difamatorias. Por el contrario, según este mismo principio, respecto de personas privadas se aplica el criterio general de cuidado que rige en el COMMON LAW, así como en el Derecho Civil nuestro. En las democracias donde existen jurisdicciones constitucionales, la tendencia ha sido establecer correctivos que hagan admisible el error de buena fe, como lo acabo de señalar, cuando se trata de hechos de objetivo interés público.

Distinto es el caso de la vida privada. En materia de vida privada los casos se plantean de una manera por completo diferente que en materia de honra. A diferencia de la injuria difamatoria, la intrusión en la vida privada no está protegida por la excepción de veracidad; ni requiere de elementos subjetivos que califiquen la acción, como en el caso de la difamación. Lo relevante en la vida privada es que existe intromisión que es objetivamente ilegítima, de acuerdo con ciertos estándares de conducta.

Pero aquí también surge la pregunta, ¿dónde tirar la línea entre el interés de mantener un ámbito de privacidad y el interés de los demás porque exista un flujo permanente de información? Yo me atrevo a proponer una regla que está muy amparada en jurisprudencias comparadas y que me parece que es razonable. Para que haya reparación se exige que la materia hecha pública, en materia de privacidad, sea altamente ofensiva y objetable por una persona razonable, de sensibilidad ordinaria y además no tiene que haber un interés legítimo en hacer disponible al público la información. Este parece ser un punto de equilibrio relativamente precario, pero que con ligeras modifi- 
caciones ha sido, como digo, aceptado por prácticamente toda la jurisprudencia comparada.

Al respecto, sin embargo, siempre se debe tener presente que el interés público de la información usualmente es más difuso y más abstracto que el interés del secreto, de modo que resulta inevitable recurrir siempre a las razones que justifican la institución de la libertad de información en el derecho y la privacidad.

Por cierto que el interés público existe respeto de la cara oculta de las personalidades que son objeto de publicidad. Conocer la otra cara es por lo general relevante respecto de personas que gozan de beneficios, pero que también tienen que soportar las cargas de ser personajes de interés público. Por eso, la privacidad no se plantea igual respecto de personajes públicos que de personas que tienen una significación y una entidad puramente privada. Ello vale especialmente para quienes se transforman en jueces de la moral; ellos se exponen necesariamente a un escrutinio público más estricto. La sola circunstancia de que la vida privada puede entrar en conflicto con la libertad de información debe excluir la hipótesis, por supuesto, de que se trata de una responsabilidad estricta, en que no es necesario un juicio acerca de la culpa (en sentido civil).

Por lo demás, de la circunstancia de que la vida privada sea un derecho consagrado por la Constitución, no se sigue necesariamente una alteración de los principios generales en materia de responsabilidad civil. Sólo se responde, en consecuencia, si el atentado a la vida privada constituye una infracción o un deber de cuidado exigible, de acuerdo con las reglas de la ordinaria prudencia.

Por último, en cuanto al daño, los casos de indemnizaciones por daño moral siempre muestran la doble cara de compensación por equivalencia del daño efectivamente sufrido y de la satisfacción de la víctima respecto del autor. De este modo, el daño moral, a diferencia del daño patrimonial, considera tanto la intensidad y gravedad del daño como la gravedad y la circunstancia de la acción. Así también en materia de daño moral, al momento de establecerse la reparación reaparece la relevancia del juicio de reproche subjetivo, que en la culpabilidad en materia civil dejar de ser un elemento definitivo.

\section{$X$}

En definitiva, la privacidad es un bien personal de gran valor. Ello sin embargo no significa que sea socialmente valioso. Los derechos establecen límites a los argumentos de utilidad. Sólo así pueden ser afirmados. Pero ¿tenemos derecho a que los demás sólo nos conozcan del modo que nosotros queremos ser conocidos?. No existen en esto respuestas absolutas. Cada sociedad tiende a dibujar la línea de un modo diferente. Hay países que en pocos años han cambiado drásticamente el acento privilegiando a la libertad de información y a la privacidad. El caso paradigmático es España; en la España de Franco la línea estaba puesta absolutamente en el ámbito de la privacidad, limitando la libertad de información; en la misma España luego se tendió al otro extremo, en que la libertad de información cubrió por completo todo aspecto de la honra y de la privacidad.

El legislador puede establecer criterios generales, como el que recién he propuesto, pero a la larga sólo es posible avanzar paso a paso, a la luz de lo que enseñan los casos, de la mano de la experiencia, pero también de la razón; y la razón creo que juega 
en estos casos particularmente sobre la base de cuáles son los argumentos que en el caso respectivo juegan en favor de la privacidad y en favor de la información.

Para eso tenemos que tener claras esas dos caras que he tratado de mostrar de la privacidad: como un bien completamente esencial para nuestra autodeterminación y para nuestra autoestima, por un lado, y por otro lado, el interés de los demás por saber respecto de nosotros como un elemento esencial para que resulte más fluida y más decente nuestra vida de relación. $Y$ eso no se puede resolver naturalmente con criterios absolutamente abstractos sino con buenas razones. 